\title{
JuAN RAMÓN SEPICH: El HiSPANISMO CATÓLICO ARGENTINO COMO TEORÍA DE LA CULTURA
}

\author{
JUAN RAMÓN SEPICH: \\ Argentine Catholic Hispanism as a Theory of Culture
}

Marcos Olalla

DOI: $10.26754 /$ ojs_arif/arif.202115538

\begin{abstract}
RESUMEN
Analizamos el pensamiento del presbítero y filósofo argentino Juan Ramón Sepich (1906-1979) en su fase hispanista (1930-1955). Destacamos la especificidad de su modo de integración al pensamiento nacionalista argentino como teórico de la cultura. Caracterizamos los principales tópicos de su discurso filosófico en esta etapa, los elementos de dicho discurso que operaron en su labor de publicista de la causa franquista y los vaivenes de sus vínculos con el primer peronismo.

Palabras ClaVE: Sepich, Hispanismo, Católico, Cultura, Franquismo.
\end{abstract}

\section{ABSTRACT}

In this work, the Hispanist phase (1930-1955) of the thought of Juan Ramón Sepich (1906-1979) - Argentinian priest and philosopher- is analyzed. The specificity of his way of integration to the Argentine nationalist thought as a cultural theorist is highlighted. The main topics of his philosophical discourse in this stage, the elements of such discourse that operated in his work as a publicist of the Francoism, and the ups and downs of his links with early Peronism are described.

KEYWORDS: Sepich, Hispanism, Catholic, Culture, Francoism. 


\section{ITINERARIO $^{1}$}

Existe un episodio en la vida académica de la provincia argentina de Mendoza que es recurrentemente recordado porque constituye un documento del estado de cosas de la política universitaria en esta provincia durante la década del 40 del siglo XX, pero cuyas proyecciones se han mantenido constantes en el tiempo. Se trata del breve paso como profesor de la Facultad de Filosofía y Letras de la Universidad Nacional de Cuyo del escritor Julio Cortázar entre mediados de 1944 y principios de 1946. En una carta a su amigo Sergio Sergi indicaba como una de las razones de su partida la incapacidad de su "estómago para aguantar la vuelta de Jesucristo a la Facultad; los Sepich y los Soaje entronizados" (Montes-Bradley 2008: 285).

Guido Soaje Ramos y Juan Ramón Sepich fueron filósofos de gran influjo en el mundo académico de la región. Sobre ellos orbitó una red de profesores católicos de derecha que hacia la segunda mitad de la década del 30 asumirían la causa del nacional-catolicismo español como su patria intelectual.

La coyuntura específica de aquella carta de Cortázar es el momento en que se producía el triunfo de Perón en las elecciones de febrero de 1946. Para entonces el elenco de profesores de derecha que actuaba en el campo de las humanidades en esta universidad ya había consolidado en su imaginario a la "nación católica" como un vector de convergencia específico con el peronismo, respecto del cual siempre recelaría por sus atributos plebeyos.

Juan Ramón Sepich fue una figura clave en la que podemos ver reflejados este tipo de posicionamientos y sus consecuentes tensiones. Su referencia política no se hallaba en Perón como sí en la estructura de gobierno surgida del golpe de junio de 1943. Fruto de esta identificación sería su paso por la Universidad de Buenos Aires, por el Ministerio de Justicia e Instrucción Pública de la Nación y por el Colegio Nacional Buenos Aires.

De este último paso existe un registro en la misma clave de la referencia cortazariana en las memorias de Tulio Halperín Donghi (2008: 123-129). En una operación que tiene mucho de condensación el historiador refleja en tono de comedia lo sucedido en torno del nombramiento de Sepich como rector del

\footnotetext{
1 Este artículo constituye una versión ampliada de un texto que aparecerá publicado en el libro Repensar la filosofía argentina. Lecturas, figuras y apropiaciones a mediados del siglo xx, editado por Marisa Muñoz y Aldana Contardi en la ciudad de Buenos Aires por la editorial Prometeo, de próxima aparición.
} 
colegio, a quien los alumnos se resistirían en riguroso "silencio" con una serie de gestos de micro-rebeldía, deliberadamente consentidos por todos los agentes de esta prestigiosa institución hasta el definitivo alejamiento del presbítero (Altamirano 2012: 18).

Se produce así una notable convergencia entre las valoraciones de Halperín Donghi y Jorge Abelardo Ramos. Este último presentaba como desvaríos del elenco de nacionalistas católicos en el gobierno de la llamada "Revolución de Junio" a sus pretensiones de redimir a la política educativa nacional de todo resabio ilustrado. No obstante Ramos interpreta esta divergencia como índice de un desajuste destinado a consumarse, luego de la conformación del peronismo, entre el nacionalismo oligárquico y la matriz popular de este movimiento (Ramos 2006: 36).

En el extremo opuesto de la escena ideológica es la afirmación de la estructuración jerárquica y natural del orden social y político lo que extraña del pensamiento del último Sepich el historiador de las ideas políticas Juan Fernando Segovia. En su balance acerca de la significativa presencia de los intelectuales católicos en Mendoza en la década del 40, suscitado por la semblanza de Rubén Calderón Bouchet, acendrado referente del carlismo —uno de los vectores más influyentes del tradicionalismo católico- incluye al presbítero, aunque deba aclarar: "el de los buenos tiempos y la buena doctrina" (2015: 859), en un artículo aparecido en Verbo, probablemente la publicación de mayor ascendiente de esta corriente. En efecto, la relativa autonomía con la que Sepich se movió desde mediados de la década del 50 en adelante lo alejó de la red del tradicionalismo, sin que ello supusiese un desplazamiento en el registro político conservador de su discurso filosófico.

Celina Fares, historiadora intelectual del nacionalismo mendocino (2011a, 2011b, 2016 y 2017) ofrece una clave para comprender la dificultad para los tradicionalistas católicos a la hora de procesar el legado de Sepich en su condición de "intelectual/clerc" (2016: 292). Sin abandonar nunca su sustrato católico, en una versión sostenidamente conservadora, la trayectoria de Sepich se tornaría en cierta medida heterodoxa al contacto con la filosofía de Heidegger primero y de Hegel después, hacia el final de su vida.

Había nacido en 1906 en Buenos Aires. Entre 1923 y 1930 completó su formación en Filosofía y Teología en el Seminario Pontificio de Buenos Aires y la Universidad Gregoriana de Roma. En la década del 30 se desempeñaría como profesor en la Facultad de Filosofía del Seminario en el que había obtenido los títulos de doctor (1926 en Filosofía y 1930 en Teología). La década del 30 sería clave 
en la integración de Sepich como una figura destacada al elenco de nacionalistas católicos. Tendría una activa participación entre 1932 y 1942 en los Cursos de Cultura Católica, así como también en revistas nacionalistas como Crisol, Nuestro Tiempo y Soly Luna. Bajo el sello editorial de los Cursos de Cultura Católica publicaría obras como Sobre inteligencia y cultura (1938), Introducción a la Filosofía (1942), Analítica de la forma lógica (1943) y Lecturas de Metafísica (1946), entre otras.

En 1942 se desempeñaría como profesor adjunto de Historia de la Filosofía Antigua de la Universidad de Buenos Aires. En 1943 desembarca en la Universidad Nacional de Cuyo, en la que muy rápidamente se convertiría en el hombre fuerte del régimen en su Facultad de Filosofía y Letras. Allí se convertiría en profesor, en director del Instituto de Filosofía, de la publicación de este último — la revista Philosophia- e incluso en decano.

Su condición de funcionario del régimen se haría todavía más explícita durante el año 1944. Ya en setiembre de 1943 había sido invitado a escuchar el informe del Director de la Comisión Nacional de Ayuda Escolar, Ingeniero Juan José Gómez Araujo, por disposición del Gral. Elbio Carlos Anaya, ministro de Justicia e Instrucción Pública. En esta convocatoria ante un nutrido grupo de funcionarios Sepich destaca como el único académico (Boletín del Ministerio de Justicia e Instrucción Pública 1943: 1331). Este hecho denota la intensidad de los lazos que lo unían al gobierno y en especial a aquellos en quienes se depositaba su política educativa. Por lo mismo no extraña que fuese nombrado algunos meses después, en febrero de 1944, como Director General de Enseñanza Religiosa, función desde la que se encargaría de velar por el correcto desarrollo de la materia Religión y Moral, incorporada por el régimen a la estructura curricular de los establecimientos educativos nacionales, a la que debía asignársele un lugar determinado en el esquema de horarios de las escuelas en función de lo que para tales funcionarios debía ser su eminente relevancia (Boletín del Ministerio de Justicia e Instrucción Pública 1944a: 459). En esta última función se desempeñaría sólo cuatro meses puesto que sería convocado por las autoridades del Ministerio y del grupo interventor de la Facultad de Derecho de la Universidad de Buenos Aires para hacerse cargo del rol de rector del Colegio Nacional Buenos Aires rebautizado por estas autoridades en una operación de rediseño simbólico del linaje de esta institución como Colegio Universitario de San Carlos, gesto que como indicáramos a propósito de las memorias de Halperín Donghi, fue percibido por todos sus agentes — estudiantes, preceptores, profesores y otros directivoscomo una señal de extravagancia inquietante. En este cargo la experiencia del presbítero sería igualmente efímera que la precedente. En resolución del ministro 
Rómulo Etcheverri Boneo del 9 de octubre de 1944 se desautorizaban medidas disciplinarias tomadas por Sepich con personal del Colegio y se lo hacía cesar en el cargo, siendo reemplazado por Nicolás V. Matienzo (Boletín del Ministerio de Justicia e Instrucción Pública 1944c: 1447-1448).

Para entonces, su breve paso por la Universidad de Buenos Aires se cerraría fruto de las tensiones entre reformistas y católicos integristas (Buchbinder 1997: 157-158) con su salida y vuelta a Mendoza. Entre 1946 y 1947 viajaría a Europa. Destacan de su presencia allí una serie de intervenciones que poseen el sello de su particular modulación del hispanismo reaccionario que para entonces ya era ostensiblemente el nudo de su pensamiento. A su participación en el X Congreso Internacional de Filosofía en Roma se sumaría una intervención muy celebrada en los círculos del nacional-catolicismo español en el XIX Congreso de Pax Romana. Sus vínculos institucionales con el estado español contribuyeron en su instalación como figura relevante de un conjunto de intelectuales que fungieron como publicistas de la causa hispanista en una fase de desencaje estratégico del gobierno español respecto de sus previos lazos con el nazismo en virtud de la pretensión de acercamiento de Franco a la agenda política y económica de Estados Unidos (Cfr. Delgado GómezEscalonilla 1992, 1998). En esa función se comprenden sus contribuciones en sendas revistas político-culturales de España como Alférez (1947-1949), publicación en la que el hispanismo reaccionario hacía posible la convergencia relativamente armoniosa de los vectores falangista e integrista católico, y en la longeva Arbor, revista que para esos años era ya claramente un instrumento más de la agenda publicística del Opus Dei (Pérez Embid 1952: 395ss.). En esta estancia española se afirma que contribuyó decisivamente a instalar la idea de la necesidad de dotar de un recurso institucional a la promoción del ideario hispanista fuera de España. La creación en julio de 1946 del Instituto Cultural Iberoamericano, antecedente inmediato del Instituto de Cultura Hispánica, se nutriría de aquella idea seminal (Cañelas Mas 2014: 77). Juan Carlos Goyeneche y Sepich fueron los argentinos que constituyeron el grupo de fundadores (Álvarez Romero 1963: 145).

En marzo de 1947 el presbítero volvió a Mendoza donde retomó sus funciones de profesor y director del Instituto de Filosofía en la Universidad Nacional de Cuyo. Allí comenzó a trabajar en la organización del Primer Congreso Nacional de Filosofía que se celebraría en esta provincia en 1949. Un año antes de la celebración del congreso renunció a su condición de secretario general del comité organizador producto de las disputas que en su interior se desarrollaron entre laicos y católicos, sobre todo porque los primeros veían a los segundos como "ultramontanos". Sepich había imaginado el congreso como plataforma de difusión del hispanismo. 
Esta agenda no tardaría en colisionar con la de los intelectuales ideológicamente afines al primer peronismo que veían en el "hispanismo reaccionario" un lastre completamente innecesario (Ruvituso 2015: 158ss.). Si bien Sepich fue empujado a renunciar por la oposición de buena parte del plantel de docentes cuyanos, el operador del giro en la organización de este evento académico sería Carlos Astrada (David 2004: 173). Los discípulos de Sepich, siempre pudorosos para reconocer el fondo ideológico de las disputas en torno de la organización del congreso prefieren evocar aquella renuncia de una manera ciertamente difusa como una oposición sin más a la politización del evento (Rodríguez 1974: 117). Los antagonistas del presbítero lo percibían como un académico cuya identificación ideológica tributaba más decididamente a Franco que a Perón. No obstante, la ruptura de sus lazos con el peronismo no se concretaría todavía. Entre los años 1948 y 1949 desarrollaría funciones de agregado cultural en Berna y Roma. No obstante, si dicho vínculo no se cerró definitivamente, sí se verían acrecentados sus "márgenes de autonomía" (Fares 2016: 295).

En 1950 volvería a la Argentina para ocupar el cargo de Profesor titular de Ética que obtuvo por concurso en la Facultad de Humanidades de la Universidad de La Plata de la que sería cesanteado en mayo de 1955, probablemente como resultado de la crisis de la relación entre Perón y la Iglesia Católica surgida hacia 1954. En los siguientes años desarrollaría una larga estancia en Europa con base en Madrid, Santiago de Compostela, Friburgo, Colonia y Berlín. En esta última ciudad se desempeñaría como profesor de Problemas de Iberoamérica en su Universidad Técnica.

A su vuelta, tras un breve paso por la Universidad del Salvador, se establecería nuevamente en la Universidad Nacional de Cuyo. Entre 1967 y 1978 Sepich trabajaría como profesor ordinario primero y emérito luego en la Facultad de Filosofía y Letras de la universidad mendocina, en la que no tardaría en convertirse en la principal referencia para profesores y estudiantes de derecha que recelaban tanto de la naciente filosofía de la liberación latinoamericana - que tuvo a Mendoza como uno de sus focos de irradiación-, como del tradicionalismo católico neotomista del que Sepich había comenzado a tomar distancia desde mediados de la década de 50. Su singular recepción católica del filósofo de Friburgo produjo una significativa bifurcación de su trayectoria intelectual. En la última etapa de su itinerario lo que Heidegger había abierto venía a cerrarlo una interpretación espiritualista de Hegel con la que Sepich pretendía oficiar de operador de una cierta rehabilitación del elemento cristiano en la tradición filosófica.

El presbítero retornaría a Alemania en 1978 y moriría allí un año después. 


\section{EL MOMENTO HISPANISTA}

En la composición del campo ideológico de la Argentina de la década del 30 del siglo XX la derecha, al par de su vector liberal conservador, se nutría de la convergencia entre nacionalistas e integristas católicos. La actividad intelectual y política de Sepich entre principios de los 30 y mediados del 50 se comprende como una fuente que habita las redes y órganos culturales del nacionalismo, sin que por ello se pueda dejar de distinguir con claridad que su modalidad de inserción en ellos se nutre de su interés por proveer una plataforma epistemológica para la interpretación católica de la realidad, tanto en su dimensión ontológica como en la histórica. Las intervenciones de Sepich entre 1939 y 1940 en la revista nacionalista Soly Luna obedecen a aquella singular impronta y expresan lo que Marcela Croce ha caracterizado como el elemento "intelectualista" de dicha publicación (Croce 2016: 56).

Sol y Luna fue expresión del vector católico hispanista y tradicionalista del nacionalismo argentino (Ianinni 2013: 155) y a ella contribuyó Sepich, al par de con varias reseñas, con dos artículos en los que claramente se manifiesta la singular forma de articulación de su intervención en dicha corriente ideológica. Sería un teórico, un operador de modelos teórico-filosóficos en cuyas coordenadas debían comprenderse las interpretaciones de la coyuntura histórica. Su posición se delinea como trabajo de determinación del orden de cosas sobre el que la realidad se constituiría y que actuaría como fundamento de los fenómenos históricos. El registro profundo de estos últimos sería sólo asequible por una vía filosóficotrascendental. En el artículo "Nota sobre historia de Filosofía, Fenomenología y Filosofía” (1939) Sepich se consagraría —en un gesto que anticipa inquietudes fenomenológicas que se plasmarán más intensamente en la primera mitad de la década del 50 en su recepción de la filosofía de Heidegger (1954) - a la construcción de una analítica fenomenológica en cuyo desarrollo no debiera rehuir del reconocimiento de que los signos "anuncian [...] la presencia inteligible de algo que está más allá de ellos mismos" (1939: 80). Trataba de asegurar que la fenomenología podría ser una modalidad de interpretación filosófica plausible al precio de renunciar al despliegue de su tarea en un único plano. La sofisticación fenomenológica de la interpretación no debería despojar a la filosofía de su capacidad de intelección de principios que estructuran lo real en clave ontológica, y, por lo mismo, jerárquica. Inteligencia y jerarquía son categorías que organizan la estructura categorial del discurso de Sepich en toda su obra, pero en esta etapa adquieren una modulación política específica. 
La contribución del filósofo al $\mathrm{N}^{\circ} 5$ de Sol y Luna, titulada "El problema fundamental de la cultura" es clave para comprender la matriz reaccionaria de su pensamiento, no sólo porque constituye un testimonio prístino de su registro ideológico, sino por su pretensión de sistematicidad. Ella oficia como una verdadera "teoría de la cultura". Allí Sepich afirmaba que frente a la presuntamente lamentable difuminación del concepto se impone una suerte de destilación de su forma pura y cuyo resultado antropológico es la perfectibilidad humana, auspiciada por la regencia del espíritu sobre la materia. Por lo mismo la disciplina capacitada para realizar esta operación sería la filosofía, aun cuando la cultura se desplegaría en dos planos: el antropológico y el histórico. Al primero de los mismos el presbítero lo concebía como la discriminación de las formas naturales de perfectibilidad humana. Las producciones culturales que no se correspondiesen con las señaladas formas deberían ser inteligidas como "infra o anticulturales". El segundo de estos planos es comprendido como el despliegue fáctico de aquellas producciones. El factor de indeterminación presente en este registro no implicaría la ausencia de orientación para las mismas en función de un fin que les viene desde fuera. Esta forma de historicidad invocada se configura como "tradición”, como la modalidad singular con la que la comunidad produce cultura a tono con aquella fuente de determinación de los fines buscados. Las producciones culturales que pudiesen poner en cuestión la tradición son caracterizadas como "anti-humanas". Sepich se movía entre un elitismo que hallaba su potencia en la construcción del mérito moral-especulativo y la perentoriedad inducida por su providencialismo, fruto del cual era empujado a deslizar la autoridad desde la verdad al don.

En el orden de las prácticas el intelectualismo se formulaba como constatación de la ausencia de "guía" para el estado de cosas propio de la época, todavía cuando pudieran entreverse procesos de emergencia capaces de atisbar la perfección buscada. Afirmaba:

Hoy nos es dado contemplar una evolución cultural que pugna por emerger a la superficie, pero camina sin guía de ninguna especie. La simple coordinación no basta; la armonía debe brotar como efecto natural de la unidad interior (Sepich 1940: 70).

La escritura de Sepich no es pródiga en referencias a su presente en este tipo de intervenciones, pero esta afirmación pone en evidencia una cierta idea de la función que podría caberle al tradicionalismo católico en el campo de los autoritarismos de derecha de plena vigencia a fines de la década del 30 y principios de la del 40. Frente al despliegue inorgánico de las producciones culturales y ante la ausencia de una meta que está allí desde el origen del proceso histórico se alza la 
tradición, la serie más articulada de valores a partir de los que los pueblos atisban su forma más perfecta y en función de los que se sostienen, aunque dificultosamente, en una operación caracterizada como "persistencia histórica". En este discurso en el que la historia cumple un papel apenas disimulado de soporte de consagración especulativa de un modelo trascendental se comprende la extraña paradoja de que aquella no se componga de "hechos", sino de "valores" (Id. 73).

El tradicionalismo no puede prescindir de una cierta evocación de la historicidad. Su caracterización, en tanto, siempre será arbitraria. En la capacidad de este discurso ontológico para encubrir su mecanismo de construcción reside su eficacia para ofrecer un recurso retórico de coyuntura. Empeñado en la formulación de un modelo teórico puro, Sepich debió recurrir a tópicos que podrían leerse como crípticos si no fuese por la tonalidad escolástica de su escritura. Éstos constituyen documentos de un intelectualismo extremo. Una afirmación como "la historia es también inmutable como aporte a la perfección humana, en la medida que es la realización actual de las capacidades humanas" (Id. 71) funge como testimonio de las dificultades del espiritualismo radical sepicheano para dotar a esta modalidad de tradicionalismo católico de una narrativa histórica mínimamente verosímil.

En esta última materia la aportación del presbítero se mantenía en el lugar común de la impugnación del Renacimiento y la Reforma como operadores de la desestructuración de la sociedad, motivo central de su fase más reaccionaria, pero cuya presencia se mantuvo hasta bien entrada su primera recepción heideggeriana (Sepich 1954a: 28-29). El catecismo cultural de Sepich puede sintetizarse en estos términos:

Tanto el universo como el hombre deben su estructura y ordenación a la inteligencia. El universo es cosmos — multitud ordenada — porque la inteligencia de la creación ha asignado a cada ser su unidad diferente y a la multiplicidad universal su orden y jerarquía (Sepich 1940: 81).

Y más adelante:

[E]1 mundo universal crece jerárquicamente por grados vitales, basta la inteligencia.

En el cosmos visible, el hombre es la unidad donde la inteligencia es principio de su unidad. Por eso todo el universo infrahumano va hacia el hombre; y todo el hombre va hacia la Inteligencia Creadora cuyo nombre es inefable (Id. 82).

La inteligencia es un operador semántico que oficia como fuente de una estructuración perfecta de las diferencias culturales ante el peligro de un decurso que eventualmente podría desconocer su meta y convertirse así en "excrecencia monstruosa" (Id. 83). 
Hay algo del orden de la aceleración en los acontecimientos que impactan en esta fase del pensamiento de Sepich en su monumental edificio de certezas. Por lo mismo acude al concepto de "línea rítmica" para caracterizar la existencia de una única dinámica de consecución de la perfección buscada. Sobre este fondo el filósofo formula los pares correspondientes a las fuerzas y modos de despliegue de la vida cultural. Entre inteligencia-voluntad, logos-ethos, filosofía-poesía Sepich no pudo ser más enfático acerca de cuál es el bloque de la serie en el que reside la perfección humana y sus productos. La impugnación del signo valorativo de la misma - que el presbítero no ve problemático en reducirlo al llamado "primado de la inteligencia"- es tematizado como "estado caótico" de la cultura y la política (Id. 86). En este orden de cosas "el supremo gobierno dispone y dirige las actividades de los súbditos en orden al fin universal” (Id. 89). Nadie podrá decir que Sepich desentone con la línea editorial de la publicación que en el mismo número en el que aparecía este artículo contestaba de modo virulento el cuestionamiento de Sur sobre la abundante publicidad oficial de que gozaba Sol y Luna:

Hemos luchado para que los valores de Jerarquía —que es ordenamiento-, de Justicia — que es virtud de gobierno—, de Autoridad — que es garantía—, fueran estimados por las inteligencias. [...]

Y una entidad que reúne a todos los usufructuarios de la enajenación argentina, acusa a reparticiones oficiales de ayudarnos con sus avisos; una entidad que, azorada ante las premoniciones de la hora, costea la exuberante publicidad de sus alarmas, no ya con avisos honradamente confesados, sino con recursos probablemente inconfesables. No nos importa pues, exponernos a cualquiera emergencia por aliviar la responsabilidad que, como argentinos, tenemos de disipar las tercas tinieblas que nos envuelven, frente a las dianas de urgencia de la realidad histórica. Esto podrá atraernos la ira de los mediocres, más nos agrega honor (s/p).

Probablemente de puño de Juan Carlos Goyeneche, expresión del vector más acendradamente antisemita del elenco de intelectuales vinculados a Soly Luna, esta editorial refleja la satisfacción con el curso de los acontecimientos a mediados del año 1940.

Sepich, como decíamos, era más esquivo para revelar sus imágenes de la coyuntura, pero esto no impide reconocer su plena sintonía con aquellas aseveraciones. En su teoría de la cultura indicaba entre uno de sus elementos a los "ideales", a partir de los que la labor improbus de los hombres en ocasiones acierta con el pulso prescripto por su origen y en cuya experiencia, promoción y enseñanza se dibuja un discurso concebido como forma de remisión a aquel principio, al que 
define como "humanismo perfecto e integral" (Id. 92). La particular apropiación que los pueblos hacen de tal discurso constituye su "tradición". La "decadencia" de los pueblos consiste pues en la destrucción de aquella por la acción de la "hibridación" social y cultural. Los hombres que expresan en la historia de un pueblo los valores de su tradición constituyen el elemento "ideado" de la cultura, sus "héroes". Ideales e ideados se comprenden en una determinada narrativa cuyos nudos se configuran como "mitos".

El siguiente elemento está constituido por las "normas". Aquí Sepich se ve empujado por las urgencias ideológicas a ofrecer un nivel un poco más generoso de explicitación política. Sostiene:

La evolución cultural se realiza dentro del ambiente de una organización política y jurídica determinada. La cultura, como fenómeno social, no es una igualación o nivelación de todo ciudadano. Por el contrario, supone alturas diferentes; querer hacer común la cultura de un pueblo, es destruirla en su raíz misma (Id. 95).

Así, el registro humanista del integrismo católico sepicheano encuentra su locus de enunciación en la tutela de la estructuración jerárquica de la sociedad por la vía de una presuntamente armoniosa gestión de las diferencias. En este punto es donde se produce la convergencia de nacionalismo e integrismo católico en la década del 20 y en la virtual enajenación del primero por el segundo en la década del 30. El pensamiento sepicheano en esta etapa es un testimonio cabal de esta modulación del nacionalismo argentino. El gobierno de las diferencias se despliega a partir de la consigna de la ilicitud, oportunamente informada por la naturaleza, de cualquier intento de supresión de la configuración estamental de la sociedad. Por lo mismo, a nivel de la cultura, una fuente de autorización de dicho gobierno se halla en dos figuras del último de los elementos que el presbítero destaca: los "maestros". El poeta y el filósofo son expresiones de este magisterio. En sentido estricto es imposible partir de cero en el proceso de enseñanza. La acción del poeta actúa pues como incitación. En lo poco que el espiritualismo del filósofo puede recoger del carácter dinámico de la cultura su concepto de la orientación poética es probablemente su momento más vivaz. Su denominación de dicha acción como una suerte de proceso de templado de los sujetos de la enseñanza se extrae por defecto. La categoría explícita alude a la imposibilidad de "culturalizar en frío" (Id. 96). Aun cuando el pudor del presbítero integrista le incomodase a la hora de ofrecer un concepto que incluyese el término "caliente", el entusiasmo poético constituye su imagen más lograda. No obstante, si el poeta posee el atributo de ser escuchado por la "multitud" el problema está en aquello que ella debería escuchar. 
Sepich, animado tal vez por la flamígera imagen precedente, corrige a Aristóteles. Sostiene que "no es tan exacto decir que el poeta es un imitador de la naturaleza, es más bien un imitador del Creador de la naturaleza" (Id. 97). Como es más o menos obvio se desprende de ello que el combustible no puede durar mucho. Pero la acción del filósofo viene en su auxilio, si no para encender nuevamente la llama, al menos para redimir al hombre de su error, al módico precio de la sujeción de la poesía a la inteligencia pura. "El poeta debe someter su influjo al filósofo. La primacía de la inteligencia pide que la ordenación superior quede en manos de la sabiduría, que es la corona de la filosofía" (Id. 98).

Sobre la base de esta teoría de la cultura se instala el tradicionalismo como lenguaje de un tipo de nacionalismo que fungiría como recuperador de abolengos no suficientemente reconocidos y cuyo nudo hispanista funcionaría al mismo tiempo como fuente providencial de la identidad católica de Hispanoamérica y como referencia política de coyuntura, en virtud de que la causa del nacionalcatolicismo hallaba su cauce en la dictadura de Franco.

El 13 de junio de 1944, al asumir el cargo de rector del Colegio Universitario de San Carlos, el presbítero profirió un discurso que conservamos fruto de su publicación en el Boletín del Ministerio de Justicia e Instrucción Pública de la Nación (1944b). El cambio de denominación del colegio fue decidido por el elenco de funcionarios que revistaba en el nacionalismo católico y constituía la red ideológica principal del régimen surgido del golpe de junio de 1943, entre los que se encontraba Sepich. Con esta modificación se renombraba bajo su apelativo original al Colegio Nacional Buenos Aires. Aunque el episodio constituye una anécdota de peso por su singular registro en las memorias de Halperín Donghi, no por dicho talante deja de ser un documento significativo en virtud de que constituye una circunstancia en la que Sepich no podría sino referirse a su coyuntura. La retórica con la que el filósofo acometió su discurso puede incitar a leerlo en clave de comedia pero en él hallamos una primera formulación explícita de su hispanismo.

Para el presbítero la civilización, concebida bajo el signo de la "cristiandad católica", integradora eficaz del "milagro griego y el orden romano", exige ser revalorizada mediante el reconocimiento de la mutua pertenencia a este insigne linaje, auspiciado del modo más perfecto por España. Afirma:

Y en nuestra propia estirpe, desde Pelayo, el héroe de Covadonga, pasando por los férreos capitanes de la Conquista, Adelantados, Fundadores y Virreyes, y siguiendo luego por los hidalgos criollos de la libertad, hasta la juventud militar de la actual Revolución, se continúa venerando al Dios nuestro, de belleza, de verdad y de justicia (Boletín del Ministerio de Justicia e Instrucción Pública de la Nación 1944b: 871). 
Tal vez porque la recuperación de esta tradición que orientaba a los fundadores del colegio y a su primer rector, "un preclaro sacerdote de la cristiandad católica y un patriota argentino" (Ibid.), constituye una tarea en buena medida providencial convenga, afirmar la función político-cultural del sacerdocio. Este gesto de autoafirmación podría ser interpretado sin más como mecanismo de autolegitimación, pero aquí desliza al territorio del elogio del gobierno. Así:

Bien está recordar el puesto del sacerdocio dentro del orden y la jerarquía. El sacerdocio tiene primacía docente en cuanto ejercita su ministerio en las almas y en todo lo que concierne al destino final del hombre y de las sociedades. Despojado de esta función por el naturalismo moderno, nuestra Revolución, restauradora de las tradiciones espirituales de la nacionalidad, quiere restituirlo a la dignidad civil que le pertenece (Ibid.).

Los orígenes de la patria, pretendidamente así recuperados por la Revolución de junio, revelan la importancia del saldo de cuentas con el liberalismo político y económico en su intento de "cambiarnos el alma", operación contra la que se alzaría "el linaje español del espíritu y de la sangre" (Id. 872). Todavía desconocedor de la inminente derrota de los regímenes fascistas en la conflagración mundial, el presbítero sostenía la clausura definitiva del liberalismo en la Argentina y su agonía en el mundo. Desplegaba en clave retrospectiva, por contraste con aquella doctrina, un tópico recurrente en el pensamiento latinoamericano desde 1900, como es la pretendida defección moral anglosajona en su empresa de conquista. "La España misionera no levantaba en las soledades americanas sórdidas factorías, sino ciudades con la Iglesia, el Cabildo y la Universidad" (Ibid.). La recuperación de esta herencia por la vía del desarrollo del factor criollo impulsaría el definitivo triunfo de la tradición española por sobre el influjo francés y su matriz ilustrada.

El XIX Congreso de Pax Romana — denominación de una red internacional de estudiantes católicos- constituyó una plataforma de afirmación del hispanismo católico como la vía hispánica del anticomunismo en la compleja coyuntura de aislamiento de España en la inmediata posguerra. El tono de las conferencias proferidas en dicho evento, algunas en Salamanca y otras en El Escorial, reflejaban esta impostura. La intervención de Sepich constituyó unos de los momentos más intensos de celebración de la hispanidad. Se titulaba "El universitario católico ante los problemas del Estado moderno". Si el registro de sus producciones en el campo del nacionalismo católico argentino se instalaba en la órbita de las precisiones filosóficas, en España actuaba como publicista y se lo percibió como tal. Esta actividad contribuiría a desarrollar una representación del presbítero como delegado del gobierno argentino. El presbítero retribuyó a esta representación que 
de él se hacían intelectuales, funcionarios y la prensa española con un cierto giro político en su escritura que tuvo un relativo impacto sobre sus modelos teóricos. En el texto de aquella conferencia en el señalado congreso y que luego publicara completa en el No 9 de Sapientia (1948a) ${ }^{2}$ cuestiona la configuración de una mirada antihistórica de lo real por obra de un rechazo en bloque de la modernidad. Para él no se trata de renunciar a la política en virtud de la existencia de la trama estado y modernidad, sino de redimir al Estado de sus componentes liberales. Si seis años antes el presbítero reforzaba aquellos registros en los que la historia aparecía como inmutable, aquí señala que es en este plano de las "contingencias" donde el universitario católico debe dar batalla ${ }^{3}$. La Universidad constituye una comunidad política menor dentro del Estado que la integra y subordina. La coordinación de estructuras en vistas de un fin universal exige un sustrato material que la haga posible. Frente al pulso liberal, que tiende a atomizar la comunidad política, los hispanoamericanos poseen un atributo providencial como es la unidad ofrecida por la "Hispanidad". Ella es un fenómeno moderno. En un gesto que muestra que todavía cuando la posición de Sepich es de un reaccionarismo notable existen algunas marcas que indican que su pensamiento será, en adelante, algo más permeable que otras formas de tradicionalismo católico a lidiar con los desafíos de la modernidad. La hispanidad es, en efecto, la vía católica a la modernidad, la "cristiandad moderna" (Id. 228). Esta empresa exige la movilización de una forma de agencia política en la que convergen la agenda religiosa y la gubernamental. La intervención sepicheana parece dirigida a un antagonista que se presume del propio campo católico:

¡Lejos de nosotros con sus idolillos, todos aquellos que nos predican la resignación de ser una selecta minoría enquistada, para quitarnos fuerza e impedir que cumplamos la vocación de hacer llegar a toda la tierra la voz de la verdad que nos ha sido comunicada por nuestra fe! (Id. 230).

Si en el mismo párrafo los destinatarios de esta imprecación son "banqueros" y "sociólogos", el registro general de su conferencia nos permite interpretarla, además, como una forma de intervención que pretende ordenar la dinámica interna

2 Existe el texto de las actas del Congreso publicado por la revista falangista El Escorial (1946). Pero la distancia entre las actas que ofrecen una síntesis y el texto completo es enorme.

3 "Más el Estado moderno, como natural y permanente institución contingente y variable de la vida comunitaria, es el marco dentro del cual el católico y el universitario que lo es, debe crear su historia y dar su testimonio" (Sepich 1948a: 226). 
de las derechas española e hispanoamericana. La legitimidad de esta interpretación se ve corroborada por otra afirmación que se destaca por su ostensible beligerancia:

En una comunidad política atomizada por la democracia liberal igualitaria, que históricamente ha deshecho todos los ordenamientos naturales y normales para el ejercicio de las indispensables funciones de toda convivencia humana, es previsible e inevitable que una restauración legítima de la autoridad, traiga aparejada una transitoria absorción de funciones por el Estado-gobierno, que en legítimo derecho, corresponde al Estado-comunidad. Pero ¿no es de espécimen diabólico, reclamar violentamente y con toda clase de sofismas, crear conciencia pública adversa a la sobreabundancia funcional (transitoria, por cierto) del Estado-gobierno, y por otra, crear conciencia y exigir de hecho una creciente atomización igualitaria del Estadocomunidad, sin organismos naturales y normales diferenciados para las funciones indispensables? ¿No es evidente, amén de una contradicción, un pecado satánico, toda vez que esta revuelta contra el Estado-gobierno se transforma en rebelión contra el principio mismo de autoridad? (Id. 249).

La operación se repite. No es sólo la democracia liberal el blanco de la maldición del sacerdote-filósofo. Es también una llamada a cerrar filas en torno del régimen de Francisco Franco.

Sepich delinea una imagen humanista de la Universidad como el vector espiritual de la orientación nacional. El componente espiritualista se formula como demanda de universalidad que informa la especificidad de las disciplinas. Un modo de instrumentación de este afianzamiento de una estructura jerarquizante de los saberes es su pretensión de reposición de la "Sagrada Teología" en la cátedra universitaria. Un resultado módico si se lo compara con la dimensión épica de la subordinación transitoria del Estado-comunidad en el Estado-gobierno.

El filósofo sostiene que en una concepción católica del Estado la comunidad política se estructura bajo una modalidad estamental y en ella el régimen de gobierno es el resultado de "la historia de cada pueblo" (Id. 267). De esa historia se intelige la existencia de una "cultura nacional". Otros elementos que componen la madeja del Estado son las riquezas naturales de las que dispone y los instrumentos con los que cuenta para su defensa. De esta compleja articulación de elementos Sepich deriva la necesidad de una interacción armónica entre el "sabio" y el "príncipe". De allí la relevancia que adquiere la categoría de prudencia en este discurso, puesto que ella es la operadora de la intelección de los principios supremos de la comunidad política.

En esta conferencia encontramos una de sus formulaciones más extensas de la idea de hispanidad. El entronque con lo que le había sido encomendado como 
tema exigiría algo del orden de la creatividad en un discurso secular. Por el contrario, la introducción de este elemento en la reflexión del presbítero no reviste ninguna dificultad. Un Estado redimido de su condición liberal constituiría una modalidad de recristianización de la política. El único vector existente de la cristiandad no alienada por el liberalismo sería la católica en su expresión hispanoamericana. "De la vieja Cristiandad que es raíz fundamental, sólo quedan ramas, secas unas, podridas otras. Una sola tiene todavía vida y salud: la Hispanidad” (Id. 269). Sepich caracteriza de este modo al sedimento de la obra hispánica en América en línea con fuentes que le precedieron en este uso, pero a las que el autor no suele referirse (Vizcarra 1929; Maeztu 1934/1941; Gomá 1934; García Morente 1938. Cfr. Juan-Navarro 2006, Zuleta 2000). Dicha obra se produjo bajo la orientación de un principio espiritual que ha tornado común una serie de rasgos que definen el destino y la cultura tanto de España como de Hispanoamérica.

El primero de tales rasgos es la baja incidencia de la herejía en el concierto de la Hispanidad, aspecto que es caracterizado como "espíritu de ortodoxia" (Sepich 1948a: 271). Aun cuando el liberalismo podría haber acentuado la vía herética no habría podido someter al componente católico del "espíritu nacional" (Ibid.). Otro elemento que no podía ausentarse en el tradicionalismo providencialista del filósofo es la presencia de la "subordinación de lo temporal a lo eterno". En este decurso de la argumentación sepicheana ya no es necesario explicitar que esta subordinación tiene su expresión política en el autoritarismo porque lo supone, aunque legitimado por el "espíritu de jerarquía" (Ibid.). A estos elementos se adiciona una cierta primacía de lo espiritual sobre lo material, tópico que, como dijimos, se desplegaba en clave esteticista en buena parte del americanismo literario, pero en el hispanismo sepicheano la literatura es desplazada por la religión católica, fuente de determinación del "bien común espiritual" (Id. 272). La religión también operaría en la existencia de una "comunidad idiomática". El "origen histórico" común es otro de estos elementos y aparece como moldeado por el talante "heroico" de la empresa imperial española. Sepich no abunda en clarificaciones en torno de esta modulación del hispanismo reaccionario pero lo que queda claro es que la abrumadora cantidad de significantes de esta retórica se reducen y concretan en el elemento católico-romano de la cultura hispánica.

De todos estos elementos se deriva que la unidad hispánica cristaliza como aspiración común en lo que Sepich llama "horizonte de la hispanidad”, del que debe inteligirse una modalidad concreta de instrumentación mediante la determinación de los "enemigos" de adentro y afuera. Por ello: 
Cada día que pasa, es nuestra esperanza, sus pueblos vigorizarán la conciencia de que la Cruzada de hoy, es empresa de la Hispanidad. Es la Cristiandad moderna que tiene su primer germen en esa comunidad que se ha propuesto hacer históricamente efectiva, la función ministerial de la vida política, al servicio del reino de Dios (Id. 273).

El largo itinerario teórico de la reflexión sobre el aporte universitario a la restauración de la autoridad política en clave católica tiene su pincelada contingente, su baño de facticidad en el barro de la labor improbus, en la cerril defensa del régimen de Franco, concebido como "cruzada".

En este discurso España es el camino de redención de Occidente, cuyo proyecto fundador se hallaría en la patrísitica cristiana. En el artículo "Los padres de Occidente. Significado cultural de la patrística”, aparecido en el número 3 de Sapientia — revista dirigida por un compañero de ruta de la Cursos de Cultura Católica como Octavio N. Derisi- Sepich destaca el aporte de los llamados padres de Occidente al triunfo definitivo del cristianismo sobre el paganismo en virtud de cuya derrota la historicidad se convierte en atributo exclusivo del primero (1948b).

La revista falangista Alférez (1947-1949) recogió el alto predicamento que Sepich tuvo sobre el vector más permeable al clericalismo de los jóvenes estudiantes universitarios españoles que deseaban acometer la obra de promoción cultural del franquismo. El elemento clerical de la revista — que convivía con otro menos afecto a esta dimensión del pensamiento de derecha español - se nutrió de una red surgida del XIX Congreso de Pax Romana en el que Sepich había pronunciado aquel celebrado discurso. Por ello es muy significativo que, tanto el primer artículo del primer número de febrero de 1947, como el último del número de cierre de la publicación, en enero de 1949, fueran del filósofo argentino. El primero de ellos lleva por título "Misión de la inteligencia", refleja la obsesiva idea sepicheana de la subordinación de la política a una cierta matriz de inteligibilidad que presume "ver los principios en el Principio", en lo que a las claras muestra que su discurso opera en dos frentes, el de la afirmación integrista del catolicismo en su único cauce legítimo, el hispánico, por un lado; y la de un nacionalismo espiritualista que se ubica en las antípodas de la solución maurrasiana. Sostenía:

El verbo de la Reforma, del Renacimiento y del Liberalismo ha causado esta dispersión atomizante del mundo, material, política y espiritual. Sea, pues, sustituido por el verbo de la Tradición, de la Cristiandad y del Catolicismo integral, en lo sobrenatural, en lo político, en la historia. Pero no se sustituya jamás en la dirección de la vida, a la inteligencia por la voluntad (Sepich 1947a: 1). 
El otro artículo publicado en el número 23-24 de Alférę lleva por título "La filosofía en Hispanoamérica", aunque la referencia es estrictamente a la Argentina. Sepich sale al paso de esta dificultad metodológica mediante la invocación de un punto central de su pensamiento, como es la unidad expresiva de la cultura continental, en cuyo caso las variedades nacionales no afectarían sus rasgos “esenciales". Entre estas últimas, una de las más importantes para una retórica agonística como la del presbítero, destaca las mismas amenazas para esta comunidad de naciones. El remedio ofrecido por el imaginario católico es una gobernabilidad derivada de la forma más perfecta de la inteligibilidad política como es la "sabiduría y Verbo divinos". Habría un doble movimiento en la filosofía argentina de la hora. Se trata del desarrollo de las disciplinas especulativas, al tiempo que con este recurso y ante el dramatismo de la coyuntura aquel impulso halla una expresión práctica en una suerte de "conversión del pensamiento hacia el contorno". El centro de la preocupación de este discurso es el factum de "los imperialismos capitalista y comunista". Frente a ello se esgrimen dos grandes agendas filosóficas, la germanófila del existencialismo ${ }^{4}$, testimonio de una cierta defección espiritual ${ }^{5}$ y la llamada "hispanofilial" del elenco de filósofos católicos argentinos. En esta última percibe la juventud y vitalidad de la que carecería su némesis existencialista.

La revista Mundo Hispánico constituyó un potente instrumento de difusión del franquismo en Hispanoamérica. Su inicial propulsor fue Joaquín Ruíz Giménez, quien además fungía como presidente del naciente Instituto de Cultura Hispánico. Había sido el director del XIX Congreso de Pax Romana y llegaría a ser Ministro de Educación del gobierno de Franco, fruto del avance de los sectores tradicionalistas en el régimen, para luego tomar notorias distancias a partir de la segunda mitad de la década del 50. Su vínculo con Sepich es claramente deducible de la relevancia que adquirió la presencia del argentino en el Congreso, en Alférez, así como también en la creación del Instituto de Cultura Hispánica. No extraña que en Mundo Hispánico se esperara una formulación del hispanismo en clave de divulgación por parte del presbítero. Lo hizo con un artículo breve, pero de gran circulación que había publicado unos meses antes en un folleto editado por la

${ }^{4}$ El constreñimiento de la cuestión del existencialismo a su vía alemana radica en que el blanco de esta impugnación es más que probablemente el filósofo argentino Carlos Astrada, fuentes de cuyo pensamiento eran las filosofías de Hegel, Marx y Heidegger.

5 En un artículo importante de esta fase del pensamiento de Sepich titulado "Existencialismo e historia" responsabilizaba a este último del desaliento de Europa en la inmediata posguerra (Sepich 1947c). 
Universidad Nacional de Cuyo. Su título era "España como problema y destino". En Mundo Hispánico apareció en su número 6, en el mes de julio de 1948, año en el que esta longeva revista comenzó a aparecer. Si Sepich se anticipó en el uso de la categoría "problema", a propósito de lo que luego sería el debate entre Pedro Laín Entralgo y Rafael Calvo Serer y que cristalizaría el universo de tensiones de la derecha española de fines de la década del 40, lo hizo de manera azarosa. En efecto, para él el problema no se encuentra en la configuración del modelo de integración de los elementos heterogéneos de la cultura y política hispánica, sino en la índole de la coyuntura global presente, en su "mefítica atmósfera espiritual" (Sepich 1948b: 9). Se trata de reconocer, a contramano de las narrativas empeñadas en quitarle valor a la obra civilizatoria de España, su honorífico puesto en la empresa de Occidente:

Ya no es posible continuar ese estado de conciencia. Hemos de saber si nuestro pasado remoto es una honra o una deshonra. Queremos poder tener la tranquilidad de nombrarnos como hijos de tal hogar. Pues sabemos que el honor, tan lejos hoy de ser una consoladora vigencia, es el indeleble sello que sobre el alma de los pueblos hispanoamericanos ha impreso España como primer bautismo natural para incorporarnos a la vida civilizada (Ibid.).

La hispanidad, como indicáramos, es comprendida como la obra de España en América. Su sujeto es Hispanoamérica. La novedad que pudiese surgir en esta margen del Atlántico tiene a España como depositaria, pero su agencia es difuminada en su ofrecimiento de garantías a la obra hispanoamericana.

La serie de rasgos que Sepich atribuye a la hispanidad, como la fe cristiana, los regímenes de gobernabilidad "paternales", o un estilo de vida "caballeresco" ponen de manifiesto la persistencia de un registro humanista en clave aristocratizante que denota el modo singular con el que el presbítero experimenta las tensiones entre paternalismo y elitismo de su propio pensamiento, cuando el itinerario de aquel primer polo de la tensión se nutría cada vez más de elementos plebeyos en el movimiento que, para entonces, él consideraba, el cauce para la recuperación de la matriz católica en la administración política.

El momento de mayor identificación de Sepich con el peronismo en materia de sus formulaciones teóricas lo hallamos en la conferencia que dictara en marzo de 1949 en la Universidad de Maguncia titulada "Las corrientes filosófico-espirituales en Latinoamérica, especialmente en la Argentina”. Allí el presbítero repasa la historia de la Argentina independiente como resultado de una fisura entre las élites criollas prestas a renunciar a la "forma cultural hispánica" (Sepich 1987: 33), frente al pueblo, depositario auténtico de la raíz hispánica en virtud de su "catolicidad sustantiva" 
(Id. 34). La intervención sepicheana enfatiza así el antagonismo entre el desarrollo de la dirigencia "plutócrata" hacia el liberalismo refrendado en la Constitución de 1853 y el "crisol" popular de sus dirigidos, aunque el precio de la autenticidad, nada módico por cierto, deba ser el reconocimiento de las "supremas jerarquías" (Id. 35). El arquetipo hispánico de la experiencia política depositada en la conciencia del pueblo habría contribuido y empujado a sus élites a evitar toda forma de "sedición", incluso en coyunturas revolucionarias. El desencuentro entre la dirigencia —en su empresa de dotar a la gobernabilidad de instituciones concebidas desde una matriz liberal- y el pueblo, en circunstancias críticas, se habría saldado en beneficio de este último a través de una mediación providencial. Sostiene:

La clase dirigente dispone del poder, del talento directivo y de la capacidad de orientación; el pueblo tiene su mística por dentro, y pone su contribución, su esfuerzo y su trabajo. Cuando la clase dirigente, por presión de las circunstancias internas o externas; por deficiencia de su sentido del honor o por la declinación de su vigor espiritual, claudica y se aleja de la ruta que lleva hacia la obtención de esos valores nombrados, el pueblo busca su caudillo y se levanta en contra (Id. 36).

El pueblo, guardián de la tradición, habría hecho posible la morigeración del componente liberal, racionalista y naturalista de las instituciones de gobierno desde la Batalla de Caseros en adelante. La coyuntura argentina de 1949 impulsa al presbítero a atisbar el cierre de aquella fractura entre las élites y los sectores populares. Asevera:

Llegamos a una clara oposición entre la vida de una nación y el pensamiento de su grupo dirigente; o en términos de antítesis, entre vida y pensamiento [...] Como esa ruptura no puede subsistir indefinidamente, tenía que producirse una de estas dos cosas: o la anulación del pueblo o el choque de las fuerzas.

Argentina está hace ya unos decenios ante esta segunda alternativa. Actitud que se justifica, y explica el hecho de la oposición de una nación con un carácter, para los de fuera, desconocido; pero que es, en verdad, el propio de dicho pueblo, el tradicional, el que ha dado a Argentina su fisonomía histórica y la ha sostenido en sus momentos de transición.

Dentro de ese marco, un pueblo con sentido idealista de la vida, con un empuje vital generoso y con un sentido del honor y del servicio a la causa de Dios y de la patria, mantuvo intacta la sustancia de su espíritu, aún en las adversas circunstancias que acabo de mencionar hace un instante.

Esta tensión y oposición de fuerzas tuvo que tener su momento de descompensación. Y en él estamos ahora (Id. 43-44). 
Toda la línea de la conferencia — destinada a afirmar la matriz hispanocatólica depositada en el pueblo argentino como fuente de redención política por la providencial acción de sus líderes - revela un notable tono afirmativo del curso de los acontecimientos políticos de la Argentina de 1949. Esto permite comprender el uso del concepto de "descompensación" como una ruptura del equilibrio de fuerzas precedente en dirección de la construcción de un nuevo balance, ahora ajustado a una cierta identidad entre las aspiraciones populares y el régimen de gobernabilidad de las mismas.

En 1954 Sepich publicaría dos trabajos que anticipan un giro de su filosofía desde una matriz escolástica hacia una forma de espiritualismo que recoge de Heidegger una modalidad de interpelación de la tradición filosófica, al tiempo que supone el reconocimiento que la vía tomista se hallaba lejos de ofrecer el lenguaje adecuado para dar cuenta de la historicidad de la comprensión (Sepich 1954a, 1954b). Esto no impactó inmediatamente en su agenda hispanista, como lo demuestran sus artículos "La empresa política de Occidente" (1955) e "Itinerario de Hispanoamérica” (1956). No obstante, consumada en 1954 la ruptura de la alianza entre la iglesia católica argentina y el gobierno de Perón e iniciado su giro hacia el estudio de la crisis de Occidente en las fuentes del, para Sepich, mejor de sus intérpretes, algunos tópicos que por un tiempo permanecieron latentes mientras duraron sus vínculos con el peronismo- se vieron así fortalecidos. Señala en uno de estos artículos:

La tónica moral se levanta cuando las jerarquías más elevadas se revisten de la luz y la espectabilidad que les brinda el sol y el firmamento.

Lo demás es colmena, es hormiguero, es tugurio, es cueva de topos y labor de roedores (Sepich 1955: 355).

El giro sepicheano iniciado en el 54, consagrado con una larga estancia de estudio en Europa, en la que se mantuvo sin publicar por poco más de una década, supondría su paulatino abandono del hispanismo, pero su nuevo lenguaje estaba lejos de constituir una mudanza, siquiera moderada, de su locus ideológico.

Marcos Olalla Universidad Nacional de Cuyo (Argentina) marcosolalla@gmail.com 


\section{BIBLIOGRAFÍA}

Altamirano, C. (2012): “La novela de formación de un historiador", Estudios Sociales, $\mathrm{n}^{\circ}$ 42, pp. 9-29.

Álvarez Moreno, J. M. (1963): “Asamblea de directivos de Institutos de Cultura Hispánica”, Cuadernos Hispanoamericanos, $\mathrm{n}^{\circ}$ 163-164, pp. 145-154.

Boletín del Ministerio de Justicia e Instrucción Pública de la Nación (1943): $\mathrm{n}^{\circ} 43$.

Boletín del Ministerio de Justicia e Instrucción Pública de la Nación (1944a): $\mathrm{n}^{\circ} 49$.

Boletín del Ministerio de Justicia e Instrucción Pública de la Nación (1944b): n 52.

Boletin del Ministerio de Justicia e Instrucción Pública de la Nación (1944c): $\mathrm{n}^{\circ} 56$.

BuchBinder, P. (1997): Historia de la Facultad de Filosofía y Letras. Universidad de Buenos Aires, Buenos Aires: Eudeba.

Cañelas Mas, A. (2014): “Las políticas del Instituto de Cultura Hispánica 1947-1953”, Historia Actual Online, n 33, pp. 77-91.

Croce, M. (2016): "Integralismo y catolicismo sobre fondo de vanguardia", en C. Jalif de Bertranou, A. Arpini, D. Ramaglia, M. M. Aranda y M. Muñoz (eds.), Actas V Congreso Interoceánico de Estudios Latinoamericanos y II Congreso de Filosofía y Educación en Nuestra América, Mendoza: Facultad de Filosofía y Letras Universidad Nacional de Cuyo, pp. 42-60.

DAvid, G. (2004): Carlos Astrada. La filosofía argentina, Buenos Aires: El cielo por asalto.

Delgado Gómez-Escalonilla, L. (1992): Imperio de papel: acción cultural y política exterior durante el primer franquismo, Madrid: CSIC.

Delgado Gómez-Escalonilla, L. (1998): Diplomacia franquista y política cultural hacia Iberoamérica 1939-1953, Madrid: CSIC.

FARES, M. C. (2011a): “Tradición y reacción en el sesquicentenario. La escuela sevillana mendocina". Prismas Revista de Historia Intelectual, n 15, pp. 87-104.

FARES, M. C. (2011b): "Universidad y nacionalismos en la Mendoza posperonista. Itinerarios intelectuales y posiciones historiográficas en la Facultad de Ciencia Política", Anuario IHES, n² 26, pp. 215-238.

FARES, M. C. (2016): "Por los sinuosos senderos del catolicismo integralista. Una biografía de Juan Ramón Sepich Lange”, en G. Gomes, Gabriela y V. Martín (comps.), Trayectorias de Intelectuales en el Estado. Actas de Jornadas de discusión, Los Polvorines: UNGS.

FARES, M. C. (2017): "Las caras del hispanismo: tránsitos y perfiles de intelectuales de derecha en la posguerra”, NUEVO MUNDO MUNDOS NUEVOS, URL http:/ / journals.openedition.org/nuevomundo/70537. Consultado el 17/12/2019.

García Morente, A. (1938): Idea de la Hispanidad, Buenos Aires: Espasa-Calpe.

Gomá, I. (1934): Apología de la hispanidad. Conferencias pronunciadas en Buenos Aires, URL http://hispanidad.tripod.com/goma.htm. Consultado el 15/12/2019.

Halperín Donghi, T. (2008): Son memorias, Buenos Aires: Siglo XXI. 
IANINNI, N. (2013): "Sol y Luna: una revista nacionalista-católica en el contexto de los años '30 y '40. Una definición al interior del mundo católico y del nacionalismo de derecha respecto del hispanismo, de la Guerra Civil española, del franquismo y del fascismo", Anuario del Centro de Estudios Históricos "Prof. Carlos S. A. Segreti", n 13, pp. $155-174$.

JuAn-NAvarro, S. (2006): "Una sola fe en una sola lengua: La Hispanidad como coartada ideológica en el pensamiento reaccionario español”, Hispania, n 89, pp. 392-399.

Maeztu, R. (1941): Defensa de la hispanidad, Madrid: Gráfica Universal.

Montes-Bradley, E. (2008): Cortázar sin barba, Estados Unidos: MB.

PÉrez EmbID, F. (1952): "Breve historia de la revista Arbor", Arbor, XXI, n 75, pp. 305-316.

Ramos, J. A. (2006): Revolución y contrarrevolución en la Argentina. La era del peronismo 19431976, Buenos Aires: Dirección de Publicaciones del Honorable Senado de la Nación.

Rodríguez, A. (1974): “El pensamiento filosófico del Dr. Juan R. Sepich”, Cuyo. Anuario del pensamiento argentino, $\mathrm{n}^{\circ}$ 9, pp. 116-151.

Ruvituso, C. I. (2015): Diálogos existenciales. La filosofía alemana en la Argentina peronista (1946-1955), Madrid: Iberoamericana/Vervuert.

SegoviA, J. F. (2015). "Las causas del orden político según Rubén Calderón Bouchet o de los fundamentos del pensamiento político tradicional", Verbo, n 539-540, pp. 859-878.

SEPICH, J. R. (1939): "Nota sobre historia de Filosofía, Fenomenología y Filosofía”, Soly Luna, n², pp. 65-80.

SEPICH, J. R. (1940): “El problema fundamental de la cultura”. Soly Luna, n 5, pp. 60-101.

SEPICH,J. R. (1946): "El universitario católico ante los problemas del estado moderno". Actas del XIX Congreso de Pax Romana, URL http://www.filosofia.org/mfb/1946pr22. htm. Consultado el 14/11/2019.

SEPICH, J. R. (1947a): "Misión de la inteligencia", Alférez, n 1. URL http://www.filosofia. org/hem/194/alf/ez0101.htm. Consultado el 27/11/2019.

SePiCH, J. R. (1947b): "Los padres de Occidente. Significado cultural de la patrística", Sapientia, n³, pp. 14-67.

SEPICH, J. R. (1947c): "Existencialismo e historia”, Sapientia, n 6, pp. 303-321.

SEPICH, J. R. (1948a): “La Universidad y el Estado Moderno”, Sapientia, nº 9, pp. 222-275.

SEPICH, J. R. (1948b): "España como problema y destino”, Mundo Hispánico, no 6, pp. 8-10.

Sepich, J. R. (1949): “La filosofía en Hispanoamérica”, Alférez, n 23-24. URL http:// www.filosofia.org/hem/194/alf/ez2312.htm. Consultado el 01/12/2019.

SePICH, J. R. (1954a): La filosofía de Ser y Tiempo de Martin Heidegger, Buenos Aires: Nuestro Tiempo.

SEPICH, J. R. (1954b): "Situación de Martin Heidegger en la filosofía”, Humanitas. Revista de la Facultad de Filosofía y Letras, n 4, pp. 15-112.

SEPICH, J. R. (1955): "La empresa política de Occidente", Cuadernos Hispanoamericanos, $\mathrm{n}^{\circ}$ 63, pp. 352-357. 
SEPICH, J. R. (1956): “Itinerario de Hispanoamérica”, Punta Europa, n 1, pp. 71-84.

SEPICH, J. R. (1987): “Las corrientes filosófico-espirituales en Latinoamérica, especialmente en la Argentina", Cuyo, vol. 3, pp. 31-49.

VizCARrA, Z. (1929): “La palabra Hispanidad”. La lectura dominical, n 1875, URL http:// www.filosofia.org/hem/192/9291207.htm. Consultado el 02/12/2019.

Zuleta Álvarez, E. (2000). España en América: estudios sobre la historia de las ideas en Hispanoamérica, Buenos Aires: Confluencia. 